\title{
OCORRÊNCIA DE EQUÍDEOS SOROPOSITIVOS PARA OS VÍRUS DAS ENCEFALOMIELITES E ANEMIA INFECCIOSA NO ESTADO DE MATO GROSSO
}

\section{R.M. Melo ${ }^{1 *}$, R.C. Cavalcanti ${ }^{1}$, E.M.C. Villalobos ${ }^{2}$, E.M.S. Cunha ${ }^{2}$, M.C.C.S.H. Lara ${ }^{2}$, D.M. Aguiar ${ }^{1}$}

${ }^{1}$ Universidade Federal de Mato Grosso, Faculdade de Agronomia, Medicina Veterinária e Zootecnia, Departamento de Clínica Médica Veterinária, Av. Fernando Correa da Costa, 2367, CEP78060-900, Cuiabá, MT, Brasil. E-mail: danmoura@ufmt.br

\section{RESUMO}

O presente trabalho determinou a ocorrência de equídeos com sorologia positiva para os vírus das encefalomielites virais dos tipos Leste (EEL), Oeste (EEO) e Venezuelana (EEV) e Anemia Infecciosa (AIE) nos biomas Amazônico, Pantaneiro e Cerrado do Estado de Mato Grosso. A detecção de anticorpos para AIE foi realizada em 886 soros pela prova de Imunodifusão em Gel de Ágar (IDGA), enquanto que para EEL, EEO e EEV foi realizada em 473 soros pela Microtécnica de Soroneutralização viral em culturas de células VERO. Para AIE, 46 (5,1\%) equídeos foram positivos, não sendo observados animais positivos da região amazônica e a maior frequência ocorrendo no ambiente do pantanal com 36,6\% de animais positivos $(\mathrm{P}<0,05)$. Para as encefalites virais, foram detectados 168 (35,5\%) equídeos positivos para EEL e 31 (6,5\%) para EEV. Não houve soros positivos para EEO. As maiores frequências de animais positivos para EEL foram observadas nos ambientes pantaneiro e amazônico com 45,8\% e 62,0\%, respectivamente ( $\mathrm{P}<0,05)$. Os três biomas estudados apresentaram ocorrência similar $(\mathrm{P}>0.05)$ de animais positivos para EEV, com 4,1\%,6,4\% e 10,3\% para o pantanal, cerrado e amazônia, respectivamente. Embora não apresentando equídeos reagente ao vírus da AIE na região amazônica, a presença de positivos em Mato Grosso encontra-se dentro do relatado no Brasil. O comportamento diferenciado do vírus da EEL e EEV nos três ecossistemas estudados reforça a presença de animais reservatórios, condições ambientais e climáticas que favorecem a proliferação de vetores que propiciam a infecção pelos vírus no Estado de Mato Grosso.

PALAVRAS-CHAVE: Encefalomielite viral equina, anemia infecciosa equina, sorologia, epidemiologia, equídeos, Mato Grosso.

\section{ABSTRACT}

THE OCCURRENCE OF EQUIDS SEROPOSITIVE FOR ENCEPHALOMYELITIS AND INFECTIOUS ANEMIA VIRUS IN MATOGROSSOSTATE, BRAZIL. The present work evaluated the occurrence of seropositive equids for eastern encephalomyelitis virus (EEE), western encephalomyelitis virus (WEE), Venezuelan encephalomyelitis virus (VEE) and infectious anemia virus (IAV) in the Pantanal,Savannahand Amazon biomes of MatoGrossoState, Brazil. The detection of antibodies against IAV was carried out in 886 sera of equids by the immunodiffusion test, and antibodies against EEE, WEE and VEE were evaluated in 473 sera by the seroneutralization test performed in VERO cells. The results showed 46 IAV seropositive equids (5.1\%). No sera was positive in the Amazon region, and the Pantanal biome showed a higher occurrence with $36.6 \%$ of seropositives $(\mathrm{P}<0.05)$. No sera was positive for WEE virus and 168 (35.5\%) and 31 (6.5\%) equids were positive for EEE and VEE respectively. Higher frequencies $(\mathrm{P}<0.05)$ were observed for EEE in the Pantanal and Amazon regions with $45.8 \%$ and $62.0 \%$ respectively. RegardingEEV, nodifferences were observed between thePantanal,Savannahand Amazon regions, presenting $4.1 \%, 6.4 \%$ and $10.3 \%$ respectively $(\mathrm{P}>0.05)$. Despite that IAV was not observed in equids from the Amazon, the occurrence of seropositive equids agree with the Brazilian prevalence. The differences of EEE and VEE behavior between biomes reinforce the presence of animal reservoirs, along with environmental and weather characteristics that support vector maintenance, which favor the presence of the viral infection in Mato Grosso State.

KEY WORDS: Equine encephalomyelitis virus, equine infectious anemia virus, serology, epidemiology, equids, Mato Grosso.

${ }^{2}$ Instituto Biológico, Centro de Pesquisa e Desenvolvimento de Sanidade Animal, São Paulo, SP, Brasil.

*Programa de Pós-Graduação em Ciências Veterinárias, Instituto de Defesa Agropecuária do Estado de Mato Grosso, Faculdade de Agronomia, Medicina Veterinária e Zootecnia, Universidade Federal de Mato Grosso. 


\section{INTRODUÇÃO}

OEstado de Mato Grosso desponta como um dos maiores produtores agropecuários do Brasil (IBGE, 2008), principalmente na cadeia produtora bovina. Dentro da bovinocultura, o manejo bovino é a principal finalidade do uso de equinos no Brasil, sendo empregado por aproximadamente $85 \%$ dos técnicos que trabalham a campo, chegando a movimentar anualmente no setor R\$ 4 bilhões (CONFEDERAÇ̃̃o..., 2010). Nesse contexto, os equídeos são indispensáveis na rotina diária no campo, sendo utilizados principalmente nas atividades de distribuição de sal em cochos, vacinação, vermifugação, rodeio de bovinos e transporte (CENTRO..., 2006). Dentro do Estado de Mato Grosso há três importantes ecossistemas: o Amazônico, o Cerrado e o Pantanal, cada qual possuindo características peculiares que podem influenciar no manejo dos bovinos. Um bom exemplo é o caso do Pantanal matogrossense, onde o cavalo Pantaneiro, raça naturalizada e adaptada à região, assim como os muares, constitui um elemento de grande importância para o manejo do rebanho bovino local (SANTOS et al., 1995; SANTOS et al., 2005).

Por outro lado, essas diferenças regionais podem facilitar a manutenção de agentes infecciosos, que prejudicam a equideocultura local. A região amazônica e pantaneira, por exemplo, oferecem condições ecológicas favoráveis para a manutenção dos vírus das Encefalomielites Virais Equinas Leste (EEL), Oeste (EEO) e Venezuelana (EEV), pois apresentam ampla variedade de aves nativas e migratórias, além da existência local de insetos vetores (VASCONCELOSet al.,1991). Inquéritos soro-epidemiológicos em populações de equídeos vêm demonstrando a ocorrência de anticorpos nas regiões amazônicas (Estados do Pará e Rondônia) (Heinemann et al., 2006; Aguiar et al., 2008), no pantanal sul-matogrossense (PAuvolidCorrêA et al., 2010) e no Estado de São Paulo (CunHA et al., 2009). Surtos de EEL em equídeos foram recentemente relatados na região Nordeste do Brasil (Ceará, Paraíba e Pernambuco) com mortalidade aproximada de $70 \%$ (SILva et al., 2011). Os equídeos apresentam grande suscetibilidade a esses agentes virais, podendo ser utilizados como indicadores, ou sentinelas da circulação de determinados vírus em uma área ou região.

Adicionalmente, dentre as doenças que causam impacto na equideocultura, a AIE é de ocorrência cosmopolita e é responsável por infecções crônicas persistentes, tendendo a tornar-se inaparente, caso a morte não ocorra nas fases sintomáticas (RADOSTITS et al., 2000). A AIE também pode ser transmitida por insetos hematófagos, por isso as regiões do Pantanal e da Amazônia são favoráveis para a manutenção do vírus. A transmissão também é influenciada por métodos iatrogênicos como compartilhamento de seringas, agulhas e utensílios, por isso nas regiões pantaneira e amazônica, além da maior presença de insetos hematófagos, as características locais de produção equina influenciam o controle sanitário da AIE, e os valores de prevalência nessas populações equídeas são mais elevados (Silva et al., 1999, Aguiar et al., 2008). Por outro lado, nas regiões mais secas como cerrado e/ ou caatinga, a ocorrência da doença tende a ser menor (AlmEIDA et al., 2006; Bicout et al., 2011). Não há, no Estado de Mato Grosso, informações epidemiológicas a respeito da AIE em equídeos, tampouco sua ocorrência de acordocom os diferentes biomas que compõe o território mato-grossense.

Diante do cumprimento do Programa Nacional de SanidadedosEquídeos(PNSE) edalegislaçãoreferente ao controle da AIE, Instrução Normativa MAPA $n^{\circ}$ 45, de 15 de junho de 2004 (BRASIL,2004), acreditamos que a realização de inquérito sorológico para os vírus EEL, EEO, EEV e AIE em equídeos de Mato Grosso poderá subsidiar futuros programas de controle e/ ou discutir programas já existentes. Sendo assim, o presente estudo avaliou a presença de anticorpos contra os vírus da EEL, EEV, EEO e da AIE, em soro de equídeos encaminhados em 2008 ao Laboratório de Apoio a Saúde Animal (LASA) do Instituto de defesa Agropecuária (INDEA) do Estado de Mato Grosso, nos diferentes ecossistemas matogrossense.

\section{MATERIAL E MÉTODOS}

\section{Local de estudo e amostragem}

O estudo foi realizado com 886 soros de equídeos oriundos de municípios de diferentes ecossistemas Amazônico, Pantaneiro e Cerrado do Estado de Mato Grosso, submetidos ao diagnóstico sorológico da AIE no LASA/INDEA-MT no ano de 2008.

Para a avaliação da AIE, foram contemplados 26 municípios dos três biomas (Fig. 1): Amazônia (com três propriedades) - municípios de Alta Floresta (\#1) e Vera (\#2); cerrado (130 propriedades) - municípios deSorriso (\#3), Lucas do Rio Verde (\#4), Diamantino (\#5), Alto Paraguai (\#6), Nova Olímpia (\#7), Barra do Bugres (\#8), Reserva do Cabaçal (\#9), Araputanga (\#10), São José dos Quatros Marcos (\#11), Mirassol D’Oeste (\#12), Jangada (\#13), Várzea Grande (\#14), Cuiabá (\#15), Chapada dos Guimarães (\#16), Rosário Oeste (\#17), Nova Brasilândia (\#18), Planalto da Serra (\#19), Juscimeira (\#20), Alto Araguaia (\#21) e Alto Taquari (\#22); Pantanal (sete propriedades) - município de Santo Antônio do Leverger (\#23), Barão de Melgaço (\#24), Poconé (\#25) e Cáceres (\#26). A avaliação dos vírus EEL, EEO e EEV contemplou 24 municípios, sendo excluídos após cálculo de amostragem os municípios de Mirassol D'Oeste (\#12) e Alto Paraguai (\#6). 
$\begin{array}{llllllll}0 & 118 & 236 & 354 & 472 & 590 & 708 \quad 826 & 808\end{array}$
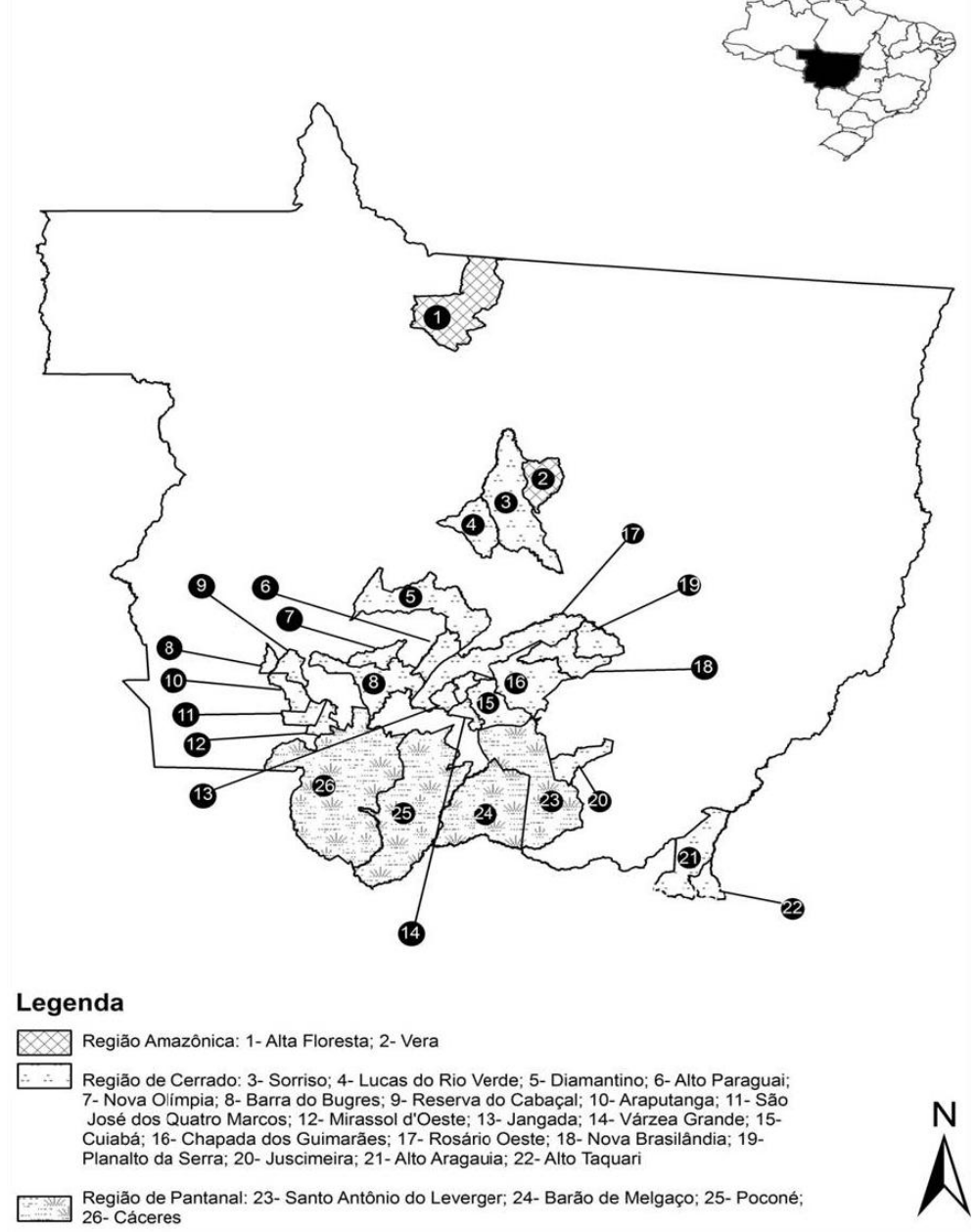

Fig. 1 - Municípios (\#1 a \#26) do Estado de Mato Grosso contemplados no estudo sobre Anemia Infecciosa Equina, Encefalomielite Viral Equina Leste, Oeste e Venezuela. Cuiabá, MT, 2011.

A amostragem dos soros foi realizada em duas etapas. Na primeira, foram avaliados os resultados da sorologia para AIE das amostras do referido banco. Para evitar duplicidade de resultados, considerouse o primeiro resultado quando havia mais de um soro por animal. Na segunda etapa, para o estudo sobre as encefalomielites virais, foram utilizados 361 soros de equinos do banco de soros do INDEA/ MT, considerando Intervalo de Confiança (IC) de $99 \%$, prevalência esperada de $50 \%$ e $4 \%$ de erro. Adicionalmente, foram testados 107 muares e cinco asininos procedentes do banco de soro. As amostras de soro foram sorteadas aleatoriamente dentro de cada bioma, considerando a proporção dos animais procedentes em cada ecossistema: aproximadamente $88 \%$ representaram o bioma cerrado e $6 \%$ os biomas amazônico e pantaneiro.

\section{Análises sorológicas}

A presença de anticorpos contra o vírus da AIE foi avaliada pela prova de Imunodifusão em Gel Ágar a 1\% (IDGA), empregando antígeno comercial do Laboratório Bruch Ltda, conforme a Instrução Normativa $\mathrm{n}^{\circ} 45$ de 15/06/2004, e a Portaria de $\mathrm{n}^{\circ} 84$ de 19/10/1992 (MAPA) erecomendações do fabricante.

A detecção de anticorpos contra os vírus EEL, EEO e EEV foi realizada pela Microtécnica de Soroneutralização viral em culturas de células VERO. Diluições seriadas de cada soro na diluição de 1:5 a 1:625 foram colocadas em placas de cultura de células com 96 orifícios e incubadas com $100 \mathrm{DICT}_{50 \%} / 25 \mu \mathrm{L}\left(4 \times 10^{3} \mathrm{DICT}_{50 \%} / \mathrm{mL}\right)$ dos vírus EEL (amostra Tatuí), EEO (amostra TR 25717) e EEV (amostra SP AN 15600), durante 1 hora a $37^{\circ}$ $\mathrm{C}$, sob atmosfera de $5 \%$ de $\mathrm{CO}_{2}$. Posteriormente, foram adicionados $100 \mu \mathrm{L}$ de uma suspensão de células VERO contendo 250.000 células/mL e as placas incubadas durante 72 horas a $37^{\circ} \mathrm{C}$ e $5 \%$ de $\mathrm{CO}_{2}$. O ponto final da reação foi determinado pela maior diluição do soro capaz de inibir $100 \%$ do efeito citopático induzido pelos vírus nas células VERO. O animal foi considerado positivo quando o título do soro foi maior ou igual a 5 . 


\section{Análise estatística}

Com auxilio do programa estatístico EpiInfo 6.04, foi realizado um estudo de associação para avaliar os resultados sorológicos e a origem do animal segundo os biomas pelo teste do Qui-quadrado $\left(\chi^{2}\right)$ ou teste exato de Fischer quando necessário.

\section{RESULTADOS}

Dos 886 soros avaliados, 758 eram de equinos, 123 eram de muares e 5 eram de asininos. Por bioma, 772 (654 equinos e 113 muares e 5 asininos) equídeos foram do cerrado, 55 (53 equinos e 2 muares) do pantanal e 59 (51 equinos e 8 muares) do amazônico.

Do total de animais testados, 46 (5,1\%) equídeos foram soropositivos para AIE (Tabela 1). Não foram observados animais positivosnoambienteamazônico. Da região do cerrado, os municípios de Alto Taquari, Araputanga, Barra do Bugres, Jangada, Mirassol D'Oeste, Nova Brasilândia, Planalto daSerra e Rosário Oesteforam responsáveis por 14,6\% (19/130) das propriedades positivas para o vírus da AIE. Do pantanal, os municípios de Barão de Melgaço e Santo Antônio do Leverger apresentaram quatro $(57,1 \%)$ fazendas com animais positivos. As diferenças observadas para propriedades entre os biomas do pantanal e do cerrado foram significativas $(\mathrm{P}<0,05)$.

Tabela 1 - Número e frequência de equídeos positivos para Anemia Infecciosa Equina por municípios avaliados nos biomas Amazônia, Cerrado e Pantanal no Estado de Mato Grosso. Cuiabá, MT, 2011.

\begin{tabular}{|c|c|c|c|c|}
\hline \multirow{2}{*}{ Bioma } & \multirow{2}{*}{ Espécie } & \multicolumn{3}{|c|}{ Animais } \\
\hline & & Testados & Positivos & $\% *$ \\
\hline \multirow{4}{*}{ Cerrado } & Equino & 654 & 21 & 3,2 \\
\hline & Muar & 113 & 4 & 3,5 \\
\hline & Asinino & 5 & 1 & 20,0 \\
\hline & Sub total & 772 & 26 & $3,36^{\mathrm{a}}$ \\
\hline \multirow{4}{*}{ Amazônia } & Equino & 51 & 0 & 0 \\
\hline & Muar & 8 & 0 & 0 \\
\hline & Asinino & 0 & 0 & 0 \\
\hline & Sub total & 59 & 0 & 0 \\
\hline \multirow{4}{*}{ Pantanal } & Equino & 53 & 20 & 37,7 \\
\hline & Muar & 2 & 0 & 0 \\
\hline & Asinino & 0 & 0 & 0 \\
\hline & Subtotal & 55 & 20 & $36,3^{\mathrm{b}}$ \\
\hline Total & & 886 & 46 & 5,1 \\
\hline
\end{tabular}

*Diferente letra na mesma coluna $=\mathrm{P}<0,05$.

Tabela 2 - Número e frequência de equídeos positivos para os vírus da Encefalomielite equina Leste (EEL) e Venezuelana (EEV) por municípios avaliados nos biomas Amazônia, Cerrado e Pantanal no Estado de Mato Grosso. Cuiabá, MT, 2011.

\begin{tabular}{|c|c|c|c|c|c|c|c|c|}
\hline \multirow{3}{*}{ Bioma } & \multirow{3}{*}{ Espécie } & \multirow{3}{*}{ № de animais testados } & \multicolumn{6}{|c|}{ № de animais reagentes } \\
\hline & & & \multicolumn{2}{|c|}{ EEO } & \multicolumn{2}{|c|}{ EEL } & \multicolumn{2}{|c|}{$\mathrm{EEV}$} \\
\hline & & & $\mathrm{n}$ & $\%$ & $\mathrm{n}$ & $\% *$ & $\mathrm{n}$ & $\% *$ \\
\hline \multirow{4}{*}{ Cerrado } & Equino & 318 & 0 & 0 & 121 & 38,0 & 19 & 5,9 \\
\hline & Muar & 97 & 0 & 0 & 17 & 17,5 & 7 & 7,2 \\
\hline & Asinino & 05 & 0 & 0 & 1 & 20,0 & 1 & 20,0 \\
\hline & Subtotal & 420 & 0 & 0 & 139 & $33,0^{\mathrm{A}}$ & 27 & $6,4^{\mathrm{A}}$ \\
\hline \multirow{4}{*}{ Amazônia } & Equino & 21 & 0 & 0 & 12 & 57,1 & 2 & 9,5 \\
\hline & Muar & 08 & 0 & 0 & 6 & 75,0 & 1 & 12,5 \\
\hline & Asinino & 0 & 0 & 0 & 0 & 0 & 0 & 0 \\
\hline & Subtotal & 29 & 0 & 0 & 18 & $62,0^{\mathrm{B}}$ & 3 & $10,3^{\mathrm{A}}$ \\
\hline \multirow{4}{*}{ Pantanal } & Equino & 22 & 0 & 0 & 10 & 45,4 & 1 & 4,5 \\
\hline & Muar & 02 & 0 & 0 & 1 & 50,0 & 0 & 0 \\
\hline & Asinino & 0 & 0 & 0 & 0 & 0 & 0 & 0 \\
\hline & Subtotal & 24 & 0 & 0 & 11 & $45,8^{\mathrm{A}, \mathrm{B}}$ & 1 & $4,1^{\mathrm{A}}$ \\
\hline Total & & 473 & 0 & 0 & 168 & $35,5^{\mathrm{a}}$ & 31 & $6,5^{b}$ \\
\hline
\end{tabular}

*Letras maiúsculas diferentes na coluna $=\mathrm{P}<0,05$;

Letra minúscula diferente na linha $=\mathrm{P}<0,05$. 
Para os vírus EEL, EEO e EEV, foram utilizados 473 soros, sendo 361 de equinos, 107 de muar e 5 asininos referentes aos biomas: amazônico (três propriedades), pantanal (sete propriedades) e cerrado (95 propriedades). Não foram observadas reações sorológicas para o vírus da EEO. Para o vírus da EEL, foram detectados 35,5\% (168/473) de animais positivos (Tabela 2). Todas as propriedades $(100 \%)$ dos municípios do bioma amazônico (Alta Floresta e Vera) apresentaram equídeos soropositivos. No cerrado, à exceção dos municípios de Reserva do Cabaçal, Cuiabá e Chapada dos Guimarães que não apresentaram propriedades positivas, 57,8\% (55/95) das fazendas dos municípios restantes tiveram equídeos reagentes. Na região do Pantanal, os quatro municípios apresentaram cinco $(71,4 \%)$ das sete propriedades com equídeos reagentes. Não foi observada diferença significativa entreas frequências observadas por propriedade $(\mathrm{P}>0,05)$.

Em relação ao vírus da EEV, 6,5\% (31/473) dos equídeos foram positivos. Das três propriedades da região Amazônica, o Município de Alta Floresta foi o que apresentou as duas $(66,6 \%)$ fazendas com equídeos reagentes. Do pantanal, o Município de Barão de Melgaço apresentou uma $(14,2 \%)$ propriedade positiva. No cerrado, Alto Araguaia, Alto Taquari, Araputanga, Jangada, Nova Brasilândia, Nova Olímpia, Planalto da Serra e Sorriso foram os municípios que apresentaram $18(18,9 \%)$ propriedades com equideos reagentes. Não foi constatada diferença significativa entre os biomas. A Tabela 2 sumariza os resultados sorológicos para o vírus da EEV segundo espécie animal e bioma.

\section{DISCUSSÃO}

O presente estudo avaliou a ocorrência de equídeos soropositivos para os vírus da AIE, EEL, EEO e EEV no Estado de Mato Grosso, representado pelos seus biomas Cerrado, Amazônia e Pantanal. Os dois últimos biomas foram representados pelos menores números de propriedades e cidades, entretanto, seguiu a proporção de soros de equideos recebidos pelo LASA/INDEA para a realização de exames sorológicos de AIE.

O valor de ocorrência (5,1\%) de equideos soropositivos para a AIE, detectada na totalidade dos animais, deve ser analisado com ressalva, pois não houve sistematização da amostragem, sendo considerados animais que solicitaram exames de AIE, o que sugere grande presença de animais elitizados (por exemplo, para obtenção de guia de transporte) ou de propriedades que possuem programas de controle para AIE. Ainda assim, os resultados apontam para os elevados índices de positividade no pantanal, os quais foram responsável por aproximadamente $43,5 \%$ das reações $(20 / 46)$, totalizando a frequência de $36,3 \%$ nesse ambiente. O presente resultado assinala o caráter endêmico da AIE na região pantaneira, pois SILVA et al. (1999) também já haviam registrado altos índices (24,8\%) em equinos do Pantanal do Estado do Mato Grosso do Sul. Por outro lado, propriedades do ambiente amazôniconão apresentaram animais soropositivos, contrastando com resultados obtidos em outras regiões da Amazônia (Aguiar et al., 2008; HeINEMANN et al., 2002). Nesse caso, deve ser considerado o baixo número de propriedades avaliadas (três propriedades), tendo em vista as características do vírus da AIE, qual requer o contato frequente entre animais, seja pelo compartilhamento de utensílios (celas e arreios) como pela transmissão por insetos hematófagos (Silva et al., 1999; Aguiar et al., 2008).

No presenteestudonão foram detectados animais reagentes para o vírus da EEO, resultado semelhante aos relatados por CunHA et al. (2009), no sul do Estado de São Paulo e Aguiar et al. 2008 no Estado de Rondônia. Outros estudos envolvendo as regiões do Pantanal e da Amazônia têm demonstrado a baixa frequência de reações sorológicas para o EEO em equinos (Iversson et al., 1993; SiLva et al., 1999; HeINEMANN et al., 2006), provavelmente refletindo baixa circulação viral nessas populações. Por outro lado, no ano de 2010, houve o relato de alta ocorrência de anticorpos contra EEOna subrregião deNhecolândia, confirmando a circulação do vírus na região sul do Pantanal. Na região amazônica, o vírus da EEO é associado à presença de aves silvestres virêmicas e isolamento do vírus. Há indícios de que a presença de mosquitos da família Culicidae esteja envolvida na transmissão a equinos e humanos (VASCONCELOS et al., 1991).

Desde a primeira detecção de anticorpos contra o vírus da EEL em equinos em 1943, no Estado de Minas Gerais (LENNETTE; Fox, 1943), os vírus das encefalomielites equinas foram estudados em diversas regiões do Brasil. No presente estudo, 35,5\% e 6,5\% dos equídeos apresentaram anticorpos contra os vírus da EEL e EEV. Dentre esses valores, as regiões da Amazônia (62\% dos animais) e do Pantanal (45,8\%) apresentaram as maiores frequências de anticorpos. Por outro lado, relata-se pela primeira vez anticorpos em equideos do cerrado mato-grossense, o que embora fosse esperado em virtude da proximidade entre os outros dois ambientes supracitados. OEstado de Mato Grosso possui ambientes propícios para a manutenção destes agentes em virtude da presença de animais reservatórios e vetores. VANCONCELOS et al. (1991) relataram diversos isolamentos do vírus EEL em aves e mosquitos, e presença de anticorpos em equinos ao longo das rodovias Belém-Brasília, Cuiabá-Santarém e transamazônica. Recentemente, PAuvolid-CorrêA et al. (2010), em concordância com 
o presente estudo, detectaram alta proporção (56\%) de anticorpos contra o vírus da EEL em equinos no Pantanal deMato Grosso doSul, a despeito deestudos anteriores que apresentaram frequências entre 1,2 a 6,7\% para os vírus da EEO e EEL, respectivamente (IvERSSON et al., 1993).

$\mathrm{O}$ vírus EEL tem sido também detectado dem casos de neuropatia em equinos nos estados de São Paulo (КотAIT et al., 1992) e Paraná (FERNANDEZ et al., 2000). Adicionalmente, no litoral Sul do Estado de São Paulo, a frequência de anticorpos contra o vírus da EEL em equideos esteve em torno de 16\% (CUNHA et al., 2009). Assim como a região amazônica e pantaneira, o ecossistema de floresta atlântica do litoral Sul paulista é propício à manutenção de mosquitos vetores, como os gêneros Aedes e Culex (ForatTini et al., 1978), ambos associados à transmissão do vírus (VANCONCELOS et al., 1991).

Anticorpos contra o vírus da EEV foram detectados em todos os ecossistemas. Como houve similaridade percentual $(\mathrm{P}>0,05)$ nos três biomas, sugere-se que essa espécie viral esteja adaptada e circule entre eles. Os resultados da região amazônica (10,3\%) estão próximos aos relatados por Aguiar et al. (2008) no Estado de Rondônia, e acima daqueles descritos por CunHA et al. (2009) em São Paulo (2,6\%). Dados referentes à ocorrência deste vírus são desconhecidos. Pertencente ao Complexo da Encefalite Equina Venezuelana e relacionado a inúmeros subtipos, este vírus é associado a casos de neuropatia em equinos do Pantanal mato-grossense (IvERSSON et al., 1993; SILVA et al., 1999). Sua manutenção na natureza envolve a circulação entre espécies de roedores, marsupiais e mosquitos, alem do próprio equino, considerado o mais importante hospedeiro virêmico (VASCONCELos et al., 1991).

Embora apresentando baixas frequências, relata-se a presença de anticorpos contra os agentes estudados entre os muares e asininos de todas as regiões avaliadas. Estes animais são frequentemente encontrados em propriedades do Estado de Mato Grosso, devido sua resistência e relevante adaptação aos sistemas de manejo de cada ecossistema. O encontro de anticorpos nestes animais merece maiores estudos, uma vez que poucas informações relativas a essas infecções são avaliadas nesses equideos.

\section{CONCLUSÃO}

Embora no presente estudo não houve a detecção de equídeos soropositivos da região amazônica mato-grossense, a ocorrência de equídeos soropositivos para AIE no Estado de Mato Grosso dentro do relatado no Brasil. Por outro lado, no ambiente do pantanal a ocorrência de animais positivos foi maior que nas outras áreas, comprovando o caráter endêmico dessa região. Equídeos dos três biomas mato-grossenses apresentaram anticorpos contra os vírus da EEL e EEV, evidenciando a circulação desses agentes nas regiões avaliadas. O comportamento diferenciado do vírus da EEL e EEV nos três ecossistemas estudados reforça a presença de animais reservatórios, condições ambientais e climáticas que favorecem a proliferação de vetores que propiciam a circulação dos vírus no Estado de Mato Grosso.

\section{AGRADECIMENTO}

À médica veterinária Andréia L.T. Melo pelo auxilio na confecção da Figura 1.

\section{REFERÊNCIAS}

AGUIAR, D.M.; CAVALCANTE, G.T.; LARA, M.C.C.S.H.; VILLLOBOS, E.M.C.; CUNHA, S.E.M.; OKUDA, L.H.; STÉFANO E.; NASSAR, A.F.C.; SOUZA, G.O., VASCONCELOS, A.S.; LABRUNA, M.B.; CAMARGO, L.M.A.; GENNARI, S.M. Prevalência de anticorpos contra agentes virais e bacterianos em eqüinos do município de Monte Negro, Rondônia, Amazônia Ocidental Brasileira. São Paulo, Brasil. Brazilian Journal of Veterinary Research and Animal Science, v45, n.4, p.269-276, 2008.

ALMEIDA, V.M.A.; GONÇALVES, V.S.P.; MARTINS, M.F.; HADDAD, J.P.A.; DIAS, R.A.; LEITE, R.C.; REIS, J.K.P. Anemia infecciosa equina: prevalência em equídeos de serviço em Minas Gerais. Arquivo Brasileiro de Medicina Veterinária e Zootecnia, v.58, n.2, p.141-148, 2006.

BICOUT, D.J.; CARVALHO, R.; CHALVET-MONFRAY, K.; SABATIER P. Distribution of equine infectious anemia in horses in the north of Minas Gerais State, Brazil. Journal of Veterinary Diagnostic Investigation, v.18, n.5, p.479-482, 2006.

BRASIL. Ministério de Abastecimento, Agricultura Pecuária. Portaria no 84 de 19/10/1992, Aprova as Normas para Credenciamento e Monitoramento de Laboratório de Anemia Infecciosa Equina. Ministério de Abastecimento, Agricultura e Pecuária Diário Oficial da União de 22/10/1992, Seção 1, página 14874.

BRASIL. Ministério de Abastecimento, Agricultura Pecuária. Instrução Normativa, no 45 de 15/06/2004, Aprova as Normas para a Prevenção ao Controle da Anemia Infecciosa Equina - A.I.E. Diário Oficial da União de 07/07/2004, Seção 1, página 7.

CENTRO DE ESTUDOS AVANÇADOS EM ECONOMIA APLICADA - CEPEA (Piracicaba, SP). Estudo do 
Complexo do Agronegócio Cavalo: Relatório Final. Piracicaba: USP/ESALQ, 2006.

CONFEDERAÇÃO NACIONAL DA AGRICULTURA E PECUÁRIA DO BRASIL - CNA. Simpósio Equestre. Brasília. Disponível em: <http:/ / www.canaldoprodutor.com.br/comunicacao/noticias/cna-defende-crescimento-do-agronegocio-cavalo>. Acesso em: 2010.

\section{COMPENDIO DE PRODUTOS VETERINÁRIOS DO SI-} DAN - CPVS. Disponível em: <http:/ /www.cpvs.com. br/cpvs/index.html>. Acesso em: 11 jun. 2010.

CUNHA, E.M.S.; VILLALOBOS, E.M.C.; NASSAR, A.F.C.; LARA, M.C.C.S.H.; PERES, N.F.; PALAZZO, J.P.C.; SILVA, A.; DE STEFANO, E.; PINO, F.A. Prevalência de anticorpos contra agentes virais em equídeos no sul do estado de São Paulo. Arquivos do Instituto Biológico, São Paulo, v.76, n.2, p.165-171, 2009. Disponível em: <http://www.biologico.sp.gov.br/docs/arq/ v76_2/cunha2.pdf>. Acesso em: 11 jun. 2010.

FERNANDEZ, Z.; RICHARTZ, R.; DA ROSA, A.T.; SOCCOL, V.T. Identificação do vírus causador de encefalomielite eqüina, Paraná, Brasil. Revista de Saúde Pública, v.34, n.3, p.232-235, 2000.

FORATTINI, O.P.; GOMES, A.C.; GALATI, E.A.B.; RABELLO, E.X.; IVERSSON, L.B. Estudos ecológicos sobre mosquitos Culicidae no sistema da serra do mar, Brasil. Revista de Saúde Pública, v.12, p.297-325, 1978.

HEINEMANN, M.B.; SOUZA, M.C.C.; CORTEZ, A.; GOTTI, T.; HOMEM, V.S.F.; FERREIRA-NETO, J.S.; SOARES, R.M.; SEQUIM, E.M.; CUNHA, S.E.M.; RICHTZENHAIN, L.J. Soroprevalência da anemia infecciosa eqüina, da arterite viral dos eqüinos e do aborto viral eqüino no município de Uruará, PA, Brasil. Brazilian Journal of Veterinary Research and Animal Science, v.39. n.1, p.50-53, 2002.

HEINEMANN, M.B.; CORTEZ, A.; SOUZA, M.C.C.; CORTEZ, A.; HOMEM, V.S.F.; FERREIRA-NETO, J.S.; SOARES, R.M.; SAKAMOTO, S.M.; CUNHA, S.E.M.; RICHTZENHAIN, L.J. Soroprevalência da encefalomielite eqüina do leste e do oeste no município de Uruará, PA, Brasil. Brazilian Journal of Veterinary Research and Animal Science, v.43, p.137-139, 2006. Suplemento.

IBGE- INSTITUTO BRASILEIRO DE GEOGRAFIA E ESTATÍSTICA. Disponível em: <http://www.ibge. gov.br/estadosat/temas.php?sigla=mt\&tema=pecuar ia2008>. Acesso em: nov. 2009.

IVERSSON, L.B.; SILVA, R.A.M.S.; TRAVASSOS da ROSA, A.P.A.; BARROS, V.L.R.S. Circulation of eastern equine encephalitis, western equine encephalitis, ilhéus, maguari and tacaíuma viruses in equines of the brasilian pantanal, south america. Revista do Instituto de Medicina Tropical de São Paulo, v.35, n.4, p.355-359, 1993.
KOTAIT, I.; PEIXOTO, Z.M.P.; COIMBRA, T.L.M.; CUNHA, S.E.M.; QUEIROZ, L.H; MACRUZ, R.; NAGAMORI, A.H. Isolamento e identificação do vírus da encefalomielite eqüina, tipo leste, em eqüinos do Estado de São Paulo, Brasil. Arquivos do Instituto Biológico, São Paulo, v.59, n.1/2, p.37-41, 1992.

LENNETTE, E.H.; FOX, J.P. Anticorpos neutralizantes para a amostra leste do vírus de Encefalomielite Equina em equídeos no Brasil. Memórias do Instituto Oswaldo Cruz, v.38, p.85-92, 1943.

PAUVOLID-CORRÊA, A.; TAVARES, F.N.; COSTA, E.V.; BURLANDY, F.M.; MURTA, M.; PELLEGRIN, A.O.; NOGUEIRA, M.F.; SILVA, E.E. Serologic evidence of the recent circulation of Saint Louis encephalitis virus and high prevalence of equine encephalitis viruses in horses in the Nhecolândia sub-region in South Pantanal, Central-West Brazil. Memórias do Instituto Oswaldo Cruz, v.105, n.6, p.829-833, 2010.

RADOSTITS, O.M.; GAY, C.C.; BLOOD, D.C.; HINCHCLIFF, K.W. Veterinary medicine. 9.ed. London: W.B. Saunders, 2000. 1877p.

SANTOS, S.A.; MAZZA, M.C.M.; SERENO, J.R.B.; ABREU, U.G.P.; SILVA, J.A. Avaliação e conservação do cavalo Pantaneiro. Corumbá: EMBRAPA - CPAP, 1995. 40p.

SANTOS, S.A.; MAZZA, M.C.M.; SERENO, J.R.B.; MAZZA, C.A.S.; PEDREIRA, A.C.M.S.; MARIANTE, A.S.; COMASTRI FILHO, J.A.; SILVA, J.A.; MARQUES, M.C.A. Descrição do manejo geral de cavalos pantaneiros na região do Pantanal. Corumbá: EMBRAPA-CPAP, 2005. $20 \mathrm{p}$.

SILVA, R.A.M.S.; DÁVILA, A.M.R.; IVERSSON, L.B.; ABREU, U.G.P. Equine viral diseases in the Pantanal, brazil. Studies carried out from 1990 to 1995. Revue Elevge de Medicine Veterinaire des Pays tropicaux, v.52, n.1, p.9-12, 1999.

SILVA, M.L.; GALIZA, G.J.; DANTAS, A.F.; OLIVEIRA, R.N.; IAMAMOTO, K.; ACHKAR, S.M.; RIET-CORREA, F. Outbreaks of Eastern equine encephalitis in northeastern Brazil. Journal of Veterinary Diagnostic Investigation, v.23, n.3, p.570-575, 2011.

VASCONCELOS, P.F.C.; TRAVASSOS DA ROSA J.F.S.; TRAVASSOS DA ROSA A.P.A.; DEGALLIER N.; PINHEIRO, F.P.; SÁ FILHO, G.C. Epidemiologia das encefalites por arbovírus na Amazônia brasileira. Revista do Instituto de Medicina Tropical de São Paulo, v.33, n.6, p.465-476, 1991.

Recebido em 28/1/11

Aceito em 4/5/12 